NASA Technical Memorandum 107243

AIAA-96-3164

\title{
Velocity and Drop Size Measurements in a Confined, Swirl-Stabilized, Combusting Spray
}

Daniel L. Bulzan

Lewis Research Center

Cleveland, Ohio

Prepared for the

32nd Joint Propulsion Conference cosponsored by AIAA, ASME, SAE, and ASEE Lake Buena Vista, Florida, July 1-3, 1996

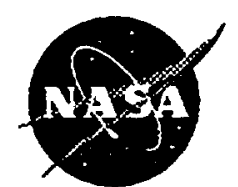

National Aeronautics and Space Administration 


\title{
VELOCITY AND DROP SIZE MEASUREMENTS IN A CONFINED, SWIRL-STABILIZED, COMBUSTING SPRAY
}

\author{
Daniel L. Bulzan \\ National Aeronautics and Space Administration \\ Lewis Research Center \\ Cleveland, Ohio 44135
}

\begin{abstract}
$\underline{\text { Abstract }}$
Drop size and velocity measurements in a confined, swirl-stabilized, reacting spray are presented. The configuration consisted of a center-mounted research air-assist atomizer surrounded by a coflowing air stream. A quartz tube surrounded the burner and provided the confinement. Both the air-assist and coflow streams had swirl imparted to them in the same direction with 45-degree-angle swirlers. The fuel and air entered the combustor at ambient temperature. The gas-phase measurements reported were obtained from the velocity of drops with a mean diameter of four microns. Heptane fuel was used for all the experiments. Measurements of drop size and velocity, gas-phase velocity and drop number flux are reported for axial distances of $2.5,5,10,15,25$, and $50 \mathrm{~mm}$ downstream of the nozzle. The measurements were performed using a two-component phase/Doppler particle analyzer. Profiles across the entire flowfield are presented.
\end{abstract}

\section{Introduction}

Combusting sprays are very important for a large number of propulsion applications. Important physical processes involved in combusting sprays are the interactions between the droplets and the gas phase, the vaporization of the droplets, and chemical reaction with associated heat release. These physical processes are all coupled and can only be completely described using numerical modeling. As part of an effort to improve the numerical modeling of spray combustion for gas turbine combustors, an experimental study has been performed to obtain a data set for a liquid-fueled combustor with simplified geometry that can be used for comparison with numerical models.

Because of their numerous practical applications, swirling flows with combustion have been studied by a large number of investigators. Earlier reviews of swirling flows both with and without combustion are presented by Chigier (Ref. 1), Syred and Beer (Ref. 2), and Lilly (Ref. 3). These papers predate the development of nonintrusive, laser-based diagnostics; consequently all of the results described were obtained using instrusive instrumentation and detailed structure measurements for these types of flows were not possible.

With the advent of newer instrumentation techniques, namely laser Doppler anemometry (LDA), velocity measurements could be obtained and additional details of the structure of these types of flows began to emerge. Laser Doppler anemometry velocity measurements in spray flames are reported by Styles and Chigier (Ref. 4) and Khalil and Whitelaw (Ref. 5). They reveal some of the flowfield structure of swirling flames but drop size and size correlated velocity measurements were not possible.

The development of the phase/Doppler particle analyzer, reported by Bachalo and Houser (Ref. 6), enabled the simultaneous measurement of droplet size and velocity. This instrument has been used by a number of investigators for measurements in spray flames in a variety of configurations. Mao et al. (Ref. 7) present phase/Doppler measurements of Sauter Mean Diameter (SMD), mean axial drop velocity, drop number density and liquid flux in a swirlstabilized unconfined spray flame using an air-assist atomizer. No gas-phase results are reported and the

"Copyright $\odot$ by the American Institute of Aeronautics and Astronautics, Inc. No copyright is asserted in the United States under Title 17, U.S. Code. The U.S. Government has a royalty-free license to exercise all rights under the copyright claimed herein for Governmental Purposes. All others rights are reserved by the copyright owner." 
measurements were taken from 10 to $75 \mathrm{~mm}$ downstream of the nozzle. McDonell and Samuelsen (Ref. 8) present measurements taken using a two-component phase/ Doppler system in a model can combustor under reacting and nonreacting conditions. The measurements were reported from 50 to $100 \mathrm{~mm}$ downstream of the nozzle. Edwards et al. (Ref.9) report drop size, drop velocity, drop size distribution, and liquid volume flux in a swirlstabilized, semiconfined flame at 10 to $100 \mathrm{~mm}$ downstream of the nozzle. Gas-phase velocities are reported at axial locations from 25 to $100 \mathrm{~mm}$ downstream using a combination of standard LDA with gas-phase seeding and phase/ Doppler measurements for $2 \mu \mathrm{m}$ drops where possible. No gas-phase results are reported at $10 \mathrm{~mm}$ downstream. Edwards and Rudoff (Ref. 10) report mean drop and gasphase velocity vectors for the same configuration. The gas-phase measurements were obtained using a standard LDA system with seeding particles and were reported to be "biased" in regions where a substantial number of drops were present. Ghaffarpour and Chehroudi (Ref. 11) present phase/Doppler measurements in a swirl-stabilized, confined combustor at axial locations from 15 to $100 \mathrm{~mm}$ downstream of the nozzle. Mean drop velocities and SMD are reported at six axial locations. Gas-phase velocity was measured using LDA without drops or combustion. Phase/ Doppler measurements of drop size and velocity as well as gas-phase velocity in a swirl-stabilized combusting spray are reported by McDonell and Samuelsen (Ref. 12). The combustion air flow was seeded in order to make the gasphase measurements. Measurements are reported at axial distances of 50,75 , and $100 \mathrm{~mm}$ downstream of the nozzle. Hassa et al. (Ref. 13) present phase/Doppler measurements in a cylindrical combustor using an airassist atomizer at axial distances from 7 to $97 \mathrm{~mm}$ downstream of the nozzle. Both drop and gas-phase velocities are reported. Gas-phase measurements in the reacting flowfield were made using the smaller drops as tracing particles. This required some judgement in order to determine what size drops should be used to represent the gas phase and also required the use of larger drops to represent the gas phase at larger axial distances due to an absence of smaller drops. Temperature measurements were also provided. McDonell et al. (Ref. 14) present extensive phase/Doppler measurements of drop size and velocity, gas-phase velocity, temperature, and methanol gas concentration for an air-assist atomizer. Measurements are reported from 7.5 to $100 \mathrm{~mm}$ downstream of the nozzle and are provided for single phase, nonreacting spray, and reacting spray cases. The spray was injected downward for all test conditions and only the air-assist stream was utilized to stabilize the flame. Bulzan (Ref. 15) reported gas-phase velocity and temperature and drop size and velocity measurements in an unconfined, swirl-stabilized, combustor using an air-assist atomizer. Measurements were reported from 2.5 to $50 \mathrm{~mm}$ downstream of the nozzle. Aluminum-oxide prticles were used as tracing particles for the gas-phase measurements.

These measurements in swirl-stabilized spray flames have been very useful in providing detailed information regarding the structure of these flowfields. Some of the data from them are also useful for the development of computer models. Most, however, do not provide enough detailed information for both the liquid and gas phases for the development of models, especially for initial conditions close to the nozzle. Hassa et al. (Ref. 13) provide the nearest measurements at $7 \mathrm{~mm}$ from the nozzle, and McDonell etal. (Ref. 14) provide measurements at $7.5 \mathrm{~mm}$ downstream. In the present study, the unconfined configuration reported in Ref. 15 was modified to provide confinement and data are presented at locations as close as $2.5 \mathrm{~mm}$ from the nozzle in order to provide initial conditions and study the two-phase flow near the injector.

\section{Experiment}

\section{Apparatus}

The combustor utilized in the present experiment is illustrated in Fig. 1. It consists of a center-mounted airassist fuel nozzle, Parker Hannifin research simplex airassist atomizer, surrounded by a coflowing air stream. The nozzle orifice diameter was $4.8 \mathrm{~mm}$. Both the air assist and the coflow air streams had swirl imparted to them using $45^{\circ}$ swirlers. The swirlers were constructed by machining $45^{\circ}$ slots into rings. Both streams were swirled in the same direction for the present study. The combustion air was not preheated and entered the combustor at $297 \pm 3 \mathrm{~K}$. The top of the air-assist nozzle was water cooled to prevent overheating of an o-ring in the nozzle assembly and maintain the atomizing air and liquid fuel at a constant inlet temperature of $297 \pm 3 \mathrm{~K}$. The temperatures of the fuel, atomizing air and coflow air streams were measured using Chromel Alumel thermocouples. Flow rates of the air streams were measured using calibrated orifices and the fuel flow rate was measured using a mass flowmeter. A single set of operating conditions was chosen where the combustor operated in a stable mode, soot was relatively minor, and measurements could be taken near the injector itself. A quartz tube with an inside diameter of $145.4 \mathrm{~mm}$ and an outside diameter of $151.6 \mathrm{~mm}$ surrounded the burner as illustrated in Fig. 1. It extended $450 \mathrm{~mm}$ above the top of the nozzle. All results reported in the present study were taken at a coflow air flow rate of $12.1 \mathrm{~g} / \mathrm{s}$, an air-assist flow rate of $1.25 \mathrm{~g} / \mathrm{s}$, and a fuel flow rate of $0.30 \mathrm{~g} / \mathrm{s}$. Uncertainty in these flow rates is estimated at \pm 5 percent. At these flow conditions the pressure drop through the nozzle was $24.8 \mathrm{kPa}$ for the fuel and $17.2 \mathrm{kPa}$ for the atomizing air. The fuel used was heptane. The 
coflow stream entered the combustor at three radial locations, passed through a honeycomb flow straightener, and then the swirler before exiting the combustor. The swirler was located $140 \mathrm{~mm}$ upstream of the combustor exit in order to minimize wakes from the swirler. The flow from the combustor discharged upwards and was exhausted to the atmosphere using an exhaust blower. The combustor was mounted vertically within a large $\left(1.8 \mathrm{~m}^{2}\right.$ by $2.4 \mathrm{~m}$ high) enclosure. The exit of the quartz tube was located $1.4 \mathrm{~m}$ from the floor of the enclosure and $1 \mathrm{~m}$ below the screened inlet of the exhaust hood at the $2.5 \mathrm{~mm}$ axial measurement location. The entire enclosure was mounted on two sets of linear bearings and was traversed using stepper motors to provide motion in two directions. The combustor assembly itself could be traversed in the vertical direction using a third stepper motor to allow measurements at all locations in the flowfield. This arrangement allowed rigid mounting of all optical components.

\section{Instrumentation}

A phase/Doppler particle analyzer was used for all velocity and size measurements. A two-component system using green $(514.5 \mathrm{~nm})$ and blue $(488.0 \mathrm{~nm})$ beams from an argon-ion laser operating at $1.25 \mathrm{~W}$ power output was used for the measurements. The transmitting optics utilized a $500 \mathrm{~mm}$ focal length lens combined with a $300 \mathrm{~mm}$ focal length collimating lens to yield a focused beam waist of $131 \mu \mathrm{m}$ for the green and $124 \mu \mathrm{m}$ for the blue lines. The fringe spacing was $6.788 \mu \mathrm{m}$ for the green and $6.667 \mu \mathrm{m}$ for the blue lines. The receiving optics were located 30 degrees off axis in the forward-scatter direction. Light was collected using a $500 \mathrm{~mm}$ focal-length $\mathrm{f} 5.4$ lens and then focused onto a $100 \mu \mathrm{m}$ by $1 \mathrm{~mm}$ long slit. Details of the instrument can be found in Ref. 6 .

In the present study, velocities of both the liquid and gaseous phases are reported. Seeding attempts using aluminum-oxide particles resulted in the inside of the quartz tube rapidly being coated with particles. In order to estimate gas-phase velocities without seeding, velocities from the smallest measured drop size group were used to represent the gas phase velocity. This is not as accurate as seeding since this technique does not provide velocities where small drops are not present and in a reacting flow where drop size is constantly changing. The drop being used for velocity measurements was initially a larger drop and would be expected to lag the gas phase more than a smaller drop. Drops with diameters from 1.2 to $6.9 \mu \mathrm{m}$ were used to represent the gas-phase velocity. Two complete traverses at each axial station were performed in order to measure all three components of velocity and provide a check on flow symmetry. Each traverse measured axial velocity and either radial or tangential velocity. Generally, 64000 measurement attempts were made at each measurement location. In regions where there were few drops, data was taken for a minimum of $600 \mathrm{sec}$. The percentage of validated measurements varied depending on the number density, size distribution, and velocities of drops at each location, but generally ranged from about 54 to 95 percent for the drop measurements.

As reported by Bicen (Ref. 16) the presence of the quartz tube has an effect on the location of the probe volume due to the refraction of the laser beams as they pass through the quartz tube. The measurements reported in this study have not been corrected to account for this refraction since it is relatively small for the present case. The equations presented by Bicen (Ref. 16) were used to estimate the effect of the quartz tube on the measurements in the present case. The largest effect of the quartz tube was to shift the axial velocity radial location by about $1 \mathrm{~mm}$. The axial velocity measurement itself was not affected. The correction for tangential velocity and radial location were less than 0.5 percent and neglected. The radial location shift and velocity correction for the radial velocity measurements were also very small and consequently neglected. Measurements using a monodisperse drop generator taken with and without the quartz tube showed no difference in measured drop size within the accuracy of the drop size measurement as long as the probe volume location was properly adjusted due to the diffraction of the laser beams by the quartz tube. In the present case, the blue probe volume location was continually adjusted to maintain acceptable coincidence with the green probe volume in all regions of the flowfield.

\section{Uncertainty Analysis}

Uncertainty in position measurements is estimated to be $\pm 0.2 \mathrm{~mm}$ for both radial and axial measurements. Uncertainty in velocity measurements was estimated by measurement repetition at a number of points in the flowfield. Drop size uncertainty in an iso-thermal monodisperse drop stream is estimated at \pm 6.5 percent based on calibration and probably is larger in an evaporating spray containing a size distribution. Since the liquid drop temperature in the flowfield could not be measured, a constant index of refraction for heptane at $298 \mathrm{~K}$ was used for all reported measurements. The refractive index is estimated to decrease by about 5 percent from $298 \mathrm{~K}$ to the boiling temperature of heptane, $371 \mathrm{~K}$. Tests with a monodisperse drop generator indicated that this change in refractive index decreases the measured drop size by 7 percent; therefore, this is the maximum size error due to the variation in refractive index. For drop velocities, uncertainty is estimated at \pm 10 percent. Drop number-flux measurement is the most difficult measurement to make 
because it requires an accurate measurement of drop size, velocity, and probe volume size. This measurement is quite difficult in the present flowfield where there are three substantial velocity components. This is complicated by the fact that the laser-beam power distribution is gaussian and probe volume size is a function of drop size. In addition, in dense regions of the spray, more than one drop can be present in the probe volume at one time causing rejection of the signal which leads to underestimation of the volume flux of the liquid phase. In the present set of measurements, integrating the liquidflux measurements across the flowfield gave 13.9 percent of the metered flowrate at $2.5,10.4$ percent at $5,30.0$ percent at 10,21.0 percent at 15, and 9.0 percent at $25 \mathrm{~mm}$ downstream of the nozzle. Since the largest volume flux should be measured at $2.5 \mathrm{~mm}$ downstream, the measurements reported for drop number flux at 2.5 and $5 \mathrm{~mm}$ downstream are certainly lower than they should be due to the high number densities at these axial locations. In order to use the data for validation it is recommended that the measured number fluxes be increased at the initial measurement location to give the measured fuel flowrate.

\section{Results and Discussion}

Mean axial velocity measurements are presented in Fig. 2. Results are presented at downstream locations of $2.5,5,10,15,25$, and $50 \mathrm{~mm}$ downstream of the nozzle. As discussed in Ref. 14, this atomizer is described as a "prompt" atomization nozzle due to the strong jet of air blasting the liquid jet. Images obtained using a short duration (less than $10 \mathrm{~ns}$ ) laser-light pulse confirmed that no ligaments were present at $2.5 \mathrm{~mm}$ downstream for this nozzle. Results are illustrated for drop diameters of 6.9, $15.4,23.8,32.3,52.0$, and $97.2 \mu \mathrm{m}$. Each drop diameter presented represents a size range of $2.8 \mu \mathrm{m}$. Velocity measurements for a particular size are not presented at locations where not enough valid measurements were obtained. This is found for many locations for the larger drop sizes. This was determined by examining the sizevelocity correlation to determine whether the measured velocity was reasonable. The specific cut-off point was generally found to be about 30 samples. Gas-phase measurements are illustrated using the smallest measured drops as previously discussed. At the axial location of $2.5 \mathrm{~mm}$ downstream, the drops are being accelerated by the air-assist stream exiting the nozzle orifice and large velocity gradients are evident. In the region of maximum axial velocity, the gas-phase velocity is higher than the drops due to the acceleration of the drops while near the edges and in the center, the drop velocities are larger than the gas phase. The smaller drops follow the gas-phase velocity more closely than larger drops. There is generally a good correlation between drop size and velocity. The larger drops have smaller velocities near the peak measured velocity at about $4 \mathrm{~mm}$ from the center and have larger velocities in the central recirculation zone and at radii larger than about $7 \mathrm{~mm}$. At $2.5 \mathrm{~mm}$ downstream, the drops are found in a relatively narrow region of the flow. At $5 \mathrm{~mm}$ downstream, results are similar to those at $2.5 \mathrm{~mm}$, but peak axial velocities have fallen slightly and the drops are found in a larger radial region of the flowfield. Very few smaller drops are found in the central region of the flowfield at $5 \mathrm{~mm}$ downstream so gas-phase measurements are generally not available in the central recirculation zone. In the shear region where the outside edge of the recirculation zone meets the air-assist stream, the velocity gradients are very large and there is a large variation in velocity depending on drop size. The larger drops have enough momentum to retain positive values of axial velocity in the recirculation zone at this axial location. At $10 \mathrm{~mm}$ downstream, no drops are found in the central recirculation region of the flowfield. The peak gas-phase velocities have decreased to about $32 \mathrm{~m} / \mathrm{s}$ and are lower than those measured for both the 6.9 and $15.4 \mu \mathrm{m}$ drops as the gas phase velocity is changing rapidly at this axial distance downstream of the nozzle. The peak velocities of drops larger than $15.4 \mu \mathrm{m}$ are lower than the gas phase since they were also lower at distances closer to the nozzle. The peak velocities of the 6.9 and $15.4-\mu \mathrm{m}$ drops are nearly identical as the drop velocities adjust to the rapidly changing gas-phase flowfield. Since the drops are vaporizing and continuously decreasing in size, the net effect is an increase in the slip velocity between the gas phase and the drops throughout the flowfield. This effect would also affect the drops used for the measurement representing the gas phase so the results presented may be biased. It is evident in the radial profile that there is a good correlation between size and axial velocity at this axial location downstream. At $15 \mathrm{~mm}$ downstream, the peak gas-phase velocity continues to decay rapidly with the result that the $15.4 \mu \mathrm{m}$ drops have the largest peak velocities, about $28 \mathrm{~m} / \mathrm{s}$ compared to $24 \mathrm{~m} / \mathrm{s}$ for the gas phase. Peak velocities for the $6.9,15.4$, and $23.8 \mu \mathrm{m}$ drops were larger than the measurements for the gas phase at this distance downstream. The size velocity correlation was still very apparent in the radial profiles at this distance downstream. Results at $25 \mathrm{~mm}$ downstream show a continuation of the same trends previously seen at 10 and $15 \mathrm{~mm}$ downstream. The peak gas-phase axial velocity has decreased to about $16 \mathrm{~m} / \mathrm{s}$ and is consistently lower than velocities for the $32.3 \mu \mathrm{m}$ and smaller drops. Only the $52 \mu \mathrm{m}$ and larger drops have peak velocities lower than the gas phase at this axial location. At $50 \mathrm{~mm}$ downstream, not enough small drops were present to estimate the gas-phase velocities. 
By $50 \mathrm{~mm}$ downstream, the flowfield has developed to the point that the drop momentum is controlling the drop velocities as the larger drops generally have the largest velocity and the $6.9 \mu \mathrm{m}$ drops have the lowest. A large central region is evident that is about $40 \mathrm{~mm}$ in radius where no drops are found.

Measurements of mean radial velocity for the drops are presented in Fig. 3 for the six drop sizes and gas phase at the same axial distances downstream of the nozzle. Results for mean radial velocity are very similar to those previously observed for axial velocity. At axial distances of 2.5 and $5 \mathrm{~mm}$ downstream, the air-assist stream is still accelerating the drops and the peak gas-phase radial velocity is larger than the drops. At the outside edge of the flowfield where the radial velocity is decreasing rapidly, the drops generally have larger velocities than the gas phase. At $10 \mathrm{~mm}$ downstream, the gas-phase radial velocity decreases rapidly with the result that the radial velocity of the $15 \mu \mathrm{m}$ drops is larger than the gas-phase and $6.9 \mu \mathrm{m}$ drops. The radial velocity for the $6.9 \mu \mathrm{m}$ drops is adjusting to the gas-phase velocity and as expected, shows less slip velocity with the gas phase. The larger drops which had smaller peak velocities continue to show the same trends, however, their velocity is now closer to the gas phase. This is especially evident for the $32 \mu \mathrm{m}$ drops. No drops are found in the central $2 \mathrm{~mm}$ radius at this axial location downstream. At $15 \mathrm{~mm}$ downstream, the trends previously illustrated at $10 \mathrm{~mm}$ downstream continue. The gas-phase mean radial velocity continues to decay while drop velocities adjust to the gas phase velocity. The $15.4 \mu \mathrm{m}$ drops again show the largest peak velocity. The central region without drops has expanded to a radius of about $10 \mathrm{~mm}$ at this axial location downstream. At $25 \mathrm{~mm}$ downstream, the $15.4 \mu \mathrm{m}$ drops continue to have the largest peak radial velocity as the gas-phase velocity continues to decrease rapidly. The peak gas-phase mean radial velocity has decreased to about $18 \mathrm{~m} / \mathrm{s}$ which is also found for the $32.3 \mu \mathrm{m}$ drops. At this location downstream, only drops $52 \mu \mathrm{m}$ and larger had mean radial velocities lower than the gas phase. At $50 \mathrm{~mm}$ downstream, not enough small drops were present to estimate the gas-phase velocity and results are only presented for the drops. The mean radial velocity has decayed considerably as well as the number of drops present.

Mean tangential velocities are presented in Fig. 4 for the gas phase and the drops. Tangential velocities are lower than the radial and axial velocities previously presented. At $2.5 \mathrm{~mm}$ downstream, the peak gas-phase mean tangential velocity is about $19 \mathrm{~m} / \mathrm{s}$ compared to about $44 \mathrm{~m} / \mathrm{s}$ for axial and $45 \mathrm{~m} / \mathrm{s}$ for radial velocity. The results for mean tangential velocity are different than previously observed for radial and axial velocity. Gasphase velocities were larger than drop velocities at all locations in the flowfield. The larger drop velocity at the outside edge of the flowfield is not observed for the tangential velocities. At $2.5 \mathrm{~mm}$ downstream there is not a large variation in mean tangential velocity with drop size near the outside edge of the flowfield. There is a large variation in the region of peak velocity and towards the center where the gradients are very steep. At $10 \mathrm{~mm}$ downstream the tangential velocities have adjusted to the gas phase velocity and the size velocity correlation is extremely uniform in all regions of the flowfield. This is shown to extend to 15 and $25 \mathrm{~mm}$ downstream locations. Again, at $50 \mathrm{~mm}$ downstream, not enough small drops are present to estimate gas-phase tangential velocity.

Figure 5 illustrates measurements of fluctuating axial velocity for both the drops and the gas-phase. Results are presented for the same axial distances downstream as for the mean velocity components and the values presented are root mean squared values (RMS). As expected, at $2.5 \mathrm{~mm}$ downstream, the gas phase generally shows larger peak fluctuating axial velocities than the drops. Since the drop size bin used to represent the gas-phase measurement is larger than those used for the drops, some of the increase is caused by a larger size group being included for these measurements. Peak fluctuating velocities are found at the radial location where the peak mean velocities are located. The measurements show a general trend toward smaller fluctuating axial velocity with increasing drop size. The very large drops, greater than $50 \mu \mathrm{m}$, tend to have much lower fluctuating axial velocities. The fluctuating axial velocity measurements do not show the same trends as previously discussed for mean axial velocity at axial distances of $10 \mathrm{~mm}$ downstream and larger. The peak gasphase fluctuating axial velocity is consistently larger than that measured for all drop sizes at all downstream locations. Near the outside edge of the flowfield, the fluctuating gasphase axial velocities were generally lower than the drops. The levels of fluctuating axial velocity decrease with increasing axial distances downstream.

Fluctuating radial velocity measurements are illustrated in Fig. 6. The results are similar to those previously illustrated for the fluctuating axial velocity measurements and are again presented as RMS values. At $2.5 \mathrm{~mm}$ downstream, the fluctuating radial velocities are larger for the gas phase than the drops. An increase in drop size generally showed a decrease in levels of fluctuating radial velocity. The peak values for fluctuating radial velocity were slightly lower than axial velocity at axial distances of $10 \mathrm{~mm}$ and larger from the nozzle. Results are presented for axial distances as large as $50 \mathrm{~mm}$ downstream. 
The measurements of fluctuating tangential velocity are presented in Fig. 7. Again, the values presented are RMS values. Fluctuating tangential velocities were smaller than fluctuating axial or radial velocities. Again, the larger drop sizes generally had lower fluctuating velocities and values decreased as the axial distance from the nozzle increased.

Drop number fluxes for the six drop sizes are presented in Fig. 8. The results are presented as the number of drops/ $\left(\mathrm{cm}^{2} \mathrm{sec}\right)$ and are plotted on a log scale. The PDPA divides the drop size distribution into 50 size bins. These 50 bins were combined into 10 drop size bins in order to make the data set manageable. In this figure, six of the 10 combined drop size bins are presented. The diameters presented represent mean values of size bins with a width of $8.5 \mu \mathrm{m}$ for the 6.9, 15.4, 23.8 and $32.3 \mu \mathrm{m}$ drops, a width of $14.2 \mu \mathrm{m}$ for the $52.0 \mu \mathrm{m}$ drops, and a width of $19.2 \mu \mathrm{m}$ for the $97.2 \mu \mathrm{m}$ drops. To adequately account for all the measured drops, the number fluxes for the remaining four sizes would also be required. The nozzle used in the present study produced a very large number of relatively small drops, evident in the results at $2.5 \mathrm{~mm}$ downstream. Number flux increases with decreasing drop size, reaching a maximum at a radius of about $6 \mathrm{~mm}$ at $2.5 \mathrm{~mm}$ downstream. The maximum number fluxes show a variation of about three orders of magnitude betweem the largest and smallest drop sizes. The radial location for the peak number flux is shifted towards the centerline with increasing drop size. Relatively few drops are found in the center of the flowfield. Drop number fluxes generally decrease with increasing axial distance downstream of the nozzle as the drops evaporate and disperse in the flowfield. Since the drops are vaporizing, drop size is continually decreasing and the drop size distribution is also changing. Compared to the distribution at $2.5 \mathrm{~mm}$ downstream, as downstream distance increases, the variation in drop number flux between the 6.9 and $15.4 \mu \mathrm{m}$ drops decreases, and by $50 \mathrm{~mm}$ downstream, the number flux of the $6.9 \mu \mathrm{m}$ drops is generally lower than all but the largest drops. A few drops are found in the center at $5 \mathrm{~mm}$ downstream, but no drops are present in the central region at larger axial distances downstream of the nozzle. Number flux profiles are very symmetric at all axial locations downstream of the nozzle indicating a relatively uniform fuel distribution in this plane of the flowfield.

\section{Conclusions}

At $2.5 \mathrm{~mm}$ downstream, negative axial velocities were measured for a small region at the center of the flowfield for the gas phase and smaller drops. Mean axial and radial velocities for the drops lag the gas-phase velocities at axial distances of 2.5 and $5 \mathrm{~mm}$ downstream. At these axial distances downstream, the slip velocity increases with increasing drop size. At 10, 15 and $25 \mathrm{~mm}$ downstream, the drop axial and radial velocities are adjusting to the rapidly changing gas-phase flowfield and the velocity correlation with drop size is not as uniform as observed at smaller distances downstream. At $15 \mathrm{~mm}$ downstream, the $23.8 \mu \mathrm{m}$ drops had the largest peak axial velocity.

Mean tangential velocities showed different trends with axial distance compared to axial and radial velocity. The measured gas-phase tangential velocity was higher than the drop velocity at all axial locations downstream of the nozzle. A size-velocity correlation is very apparent with the smaller drops showing the least amount of slip with the gas phase. At $10 \mathrm{~mm}$ downstream, the largest velocity difference between the gas phase and the drops is observed for mean tangential velocity.

Gas-phase fluctuating velocities are larger than drop fluctuating velocities. The fluctuating axial velocity was slightly larger than the fluctuating radial velocity and the fluctuating tangential velocity was smaller than the other two velocity components. Larger sized drops generally had smaller fluctuating velocities.

Drop number fluxes at $2.5 \mathrm{~mm}$ downstream illustrate the drop size distribution produced by the research airassist atomizer used in the present study. Number fluxes were directly related to drop size with smaller sizes having larger numbers of drops. The radial location for the peak drop number flux decreased with increasing drop size. The drop size distribution changed with downstream distance from the nozzle as the drops vaporized and the smaller drops showed preferential vaporization producing smaller numbers of $6.9 \mu \mathrm{m}$ drops at larger downstream distances. At $50 \mathrm{~mm}$ downstream drop number fluxes are considerably reduced.

\section{References}

1. Chigier, N.A., "Gas Dynamics of Swirling Flow in Combustion Systems," Astronautica Acta, Vol. 17, 1972, pp. 387-395.

2. Syred, N. and Beer, J., "Combustion in Swirling Flows: A Review," Combustion and Flame, Vol. 23, 1974, pp. 143-201.

3. Lilley, D.G., "Swirl Flows in Combustion: A Review," AIAA J., Vol. 15, No. 8, 1977, pp. 1063-1078.

4. Styles, A.C., and Chigier, N.A., "Combustion of Air Blast Atomized Spray Flames," Sixteenth Symposium (International) on Combustion, The Combustion Institute, 1976, pp. 619-630.

5. Khalil, E.E., and Whitelaw, J.H., "Aerodynamic and Thermouynamic Characteristics of Kerosene-Spray 
Flames," Sixteenth Symposium (International) on Combustion, The Combustion Institute, 1976, pp. 569-576.

6. Bachalo, W.D., and Houser, M.J., "Phase/Doppler Spray Analyzer for Simultaneous Measurements of Drop Size and Velocity Distributions," Optical Engineering, Vol. 23, No. 5, 1984, pp. 583-590.

7. Mao, C-P, Wang, G., and Chigier, N., "An Experimental Study of Air-Assist Atomizer Spray Flames," Twenty First Symposium (International) on Combustion, The Combustion Institute, 1986, pp. 665-673.

8. McDonell, V.G., and Samuelsen, G.S.," Application of Two-Component Phase Doppler Interferometry to the Measurement of Particle Size, Mass Flux, and Velocities in Two-Phase Flows." Twenty Second Symposium (International) on Combustion, The Combustion Institute, 1988, pp. 1961-1971.

9. Edwards, C.F., Rudoff, R.C., and Bachalo, W.D., "Measurement of Correlated Drop Size and Velocity Statistics, Size Distribution, and Volume Flux in a Steady Spray Flame,"Fifth International Symposium on the Applications of Laser Techniques to Fluid Mechanics, Lisbon, Portugal, July 1990.

10. Edwards, C.F., and RudoffR.C., "Structure of a SwirlStabilized Spray Flame by Imaging, Laser Doppler Velocimetry, and Phase Doppler Anemometry,"
Twenty Third Symposium (International) on Combustion, The Combustion Institute, 1990, pp. 1353-1359.

11. Ghaffarpour, M. and Chehroudi, B., "Experiments on Spray Combustion in a Gas Turbine Model Combustor," Combust. Sci. and Tech., Vol. 92, 1993, pp. 173-200.

12. McDonell, V.G., and Samuelsen, S., "Gas and Drop Behavior in Reacting and Non-Reacting Air-Blast Atomizer Sprays," J. Propulsion, Vol. 7, No. 5, 1991, pp. 684-691.

13. Hassa, C., Deick, A., and Eickhoff, H., "Investigation of the Two-Phase Flow in a Research Combustor under Reacting and Non-Reacting Conditions," AGARD-CP-536, May, 1993, pp. 41-1-41-12.

14. McDonell, V.G., Adachi, M., and Samuelsen, G.S., "Structure of Reacting and Non-Reacting Swirling Air-Assisted Sprays," Combust. Sci. and Tech., Vol. 82, 1992, pp. 225-248.

15. Bulzan, D.L., "Structure of a Swirl-Stabilized, Combusting Spray," J. Propulsion, Vol. 11, No. 6, 1995, pp. 1093-1102.

16. Bicen, A. F., "Refraction Correction for LDA Measurements in Flows with Curved Optical Boundaries,"TSI Quarterly, Vol. viii, Issue 2, AprilJune 1982. 


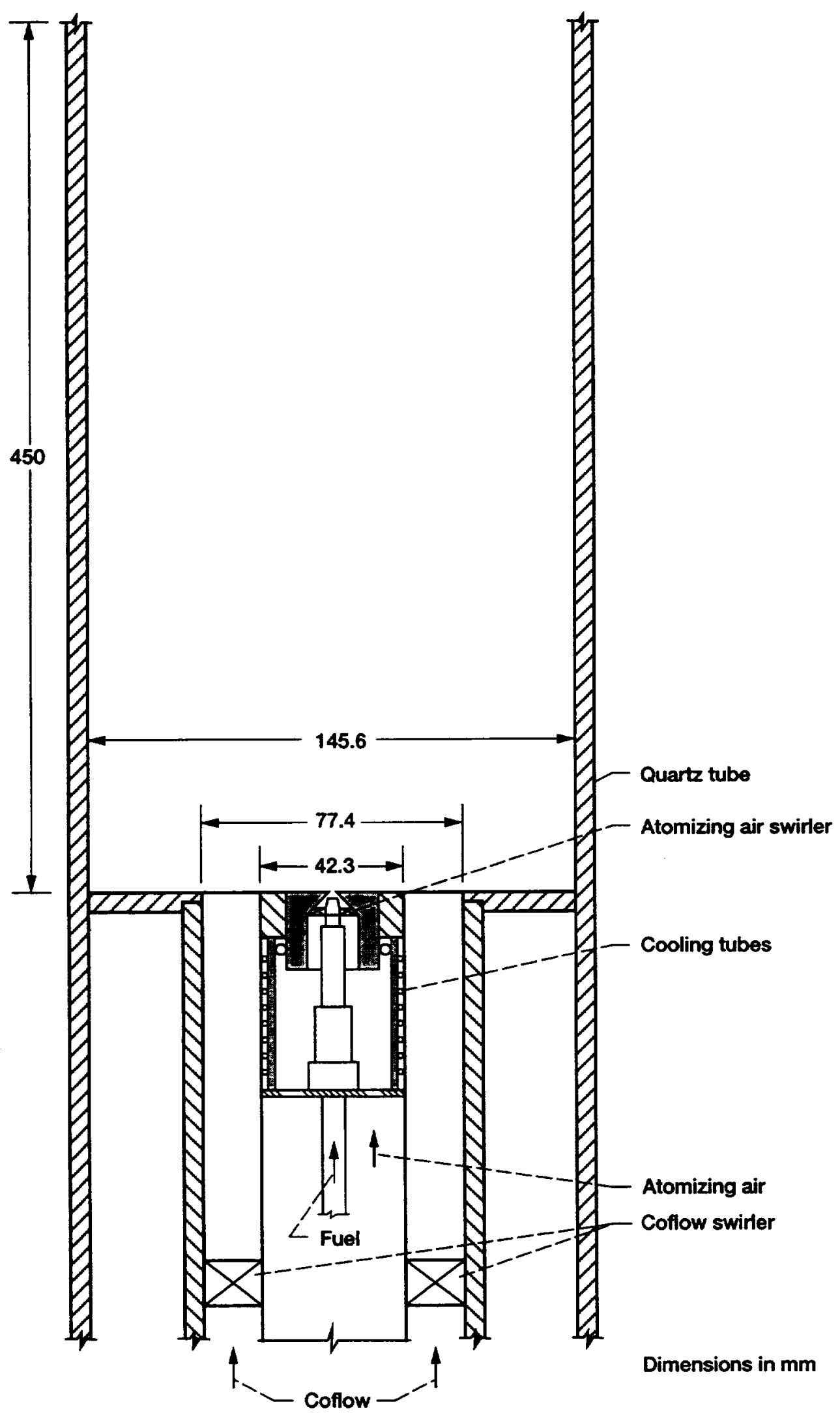

Figure 1. -Schematic drawing of the combustor.

8

American Institute of Aeronautics and Astronautics 

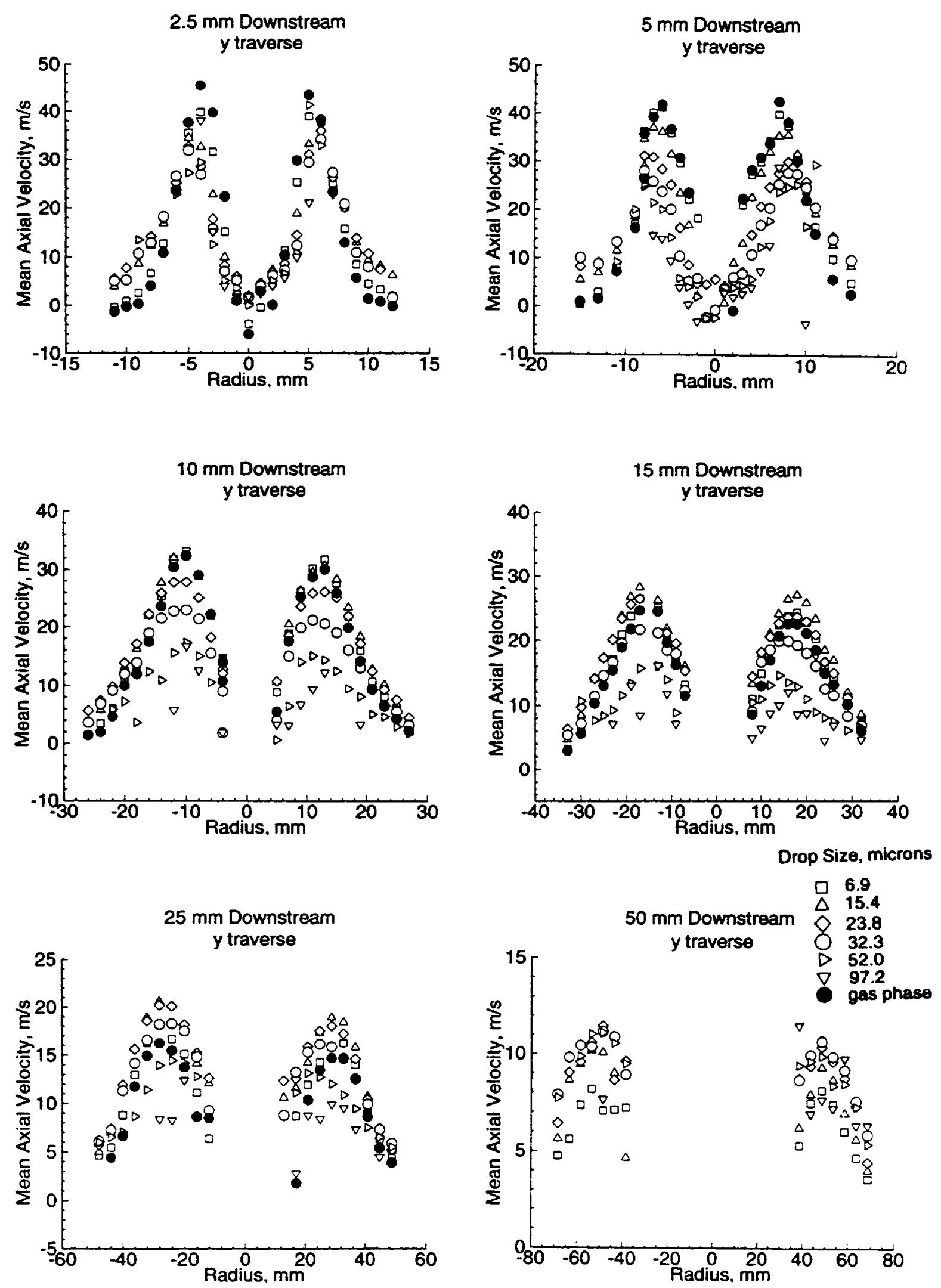

Figure 2.- Mean axial velocity profiles. 

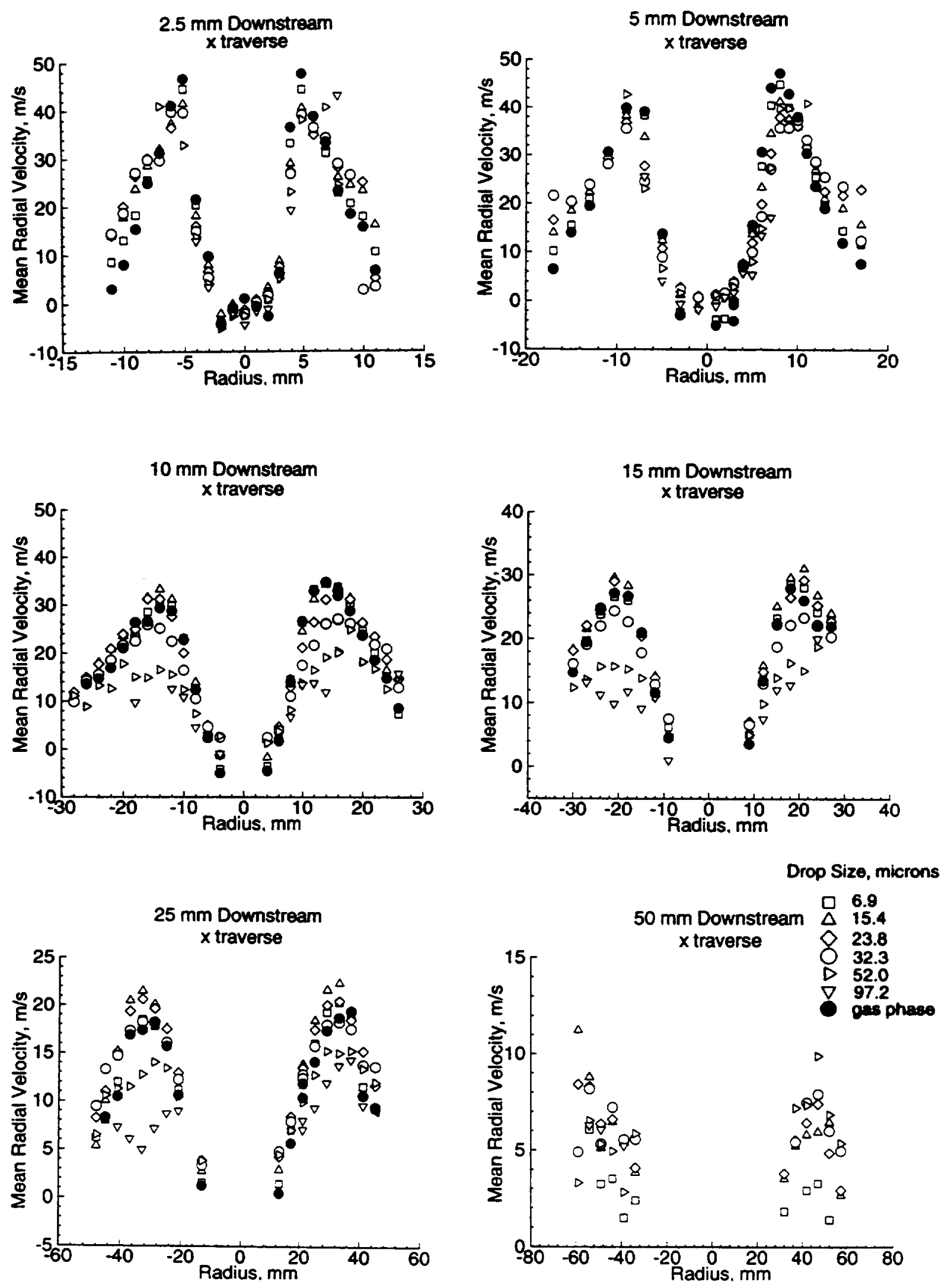

Figure 3.- Mean radial velocity profiles. 

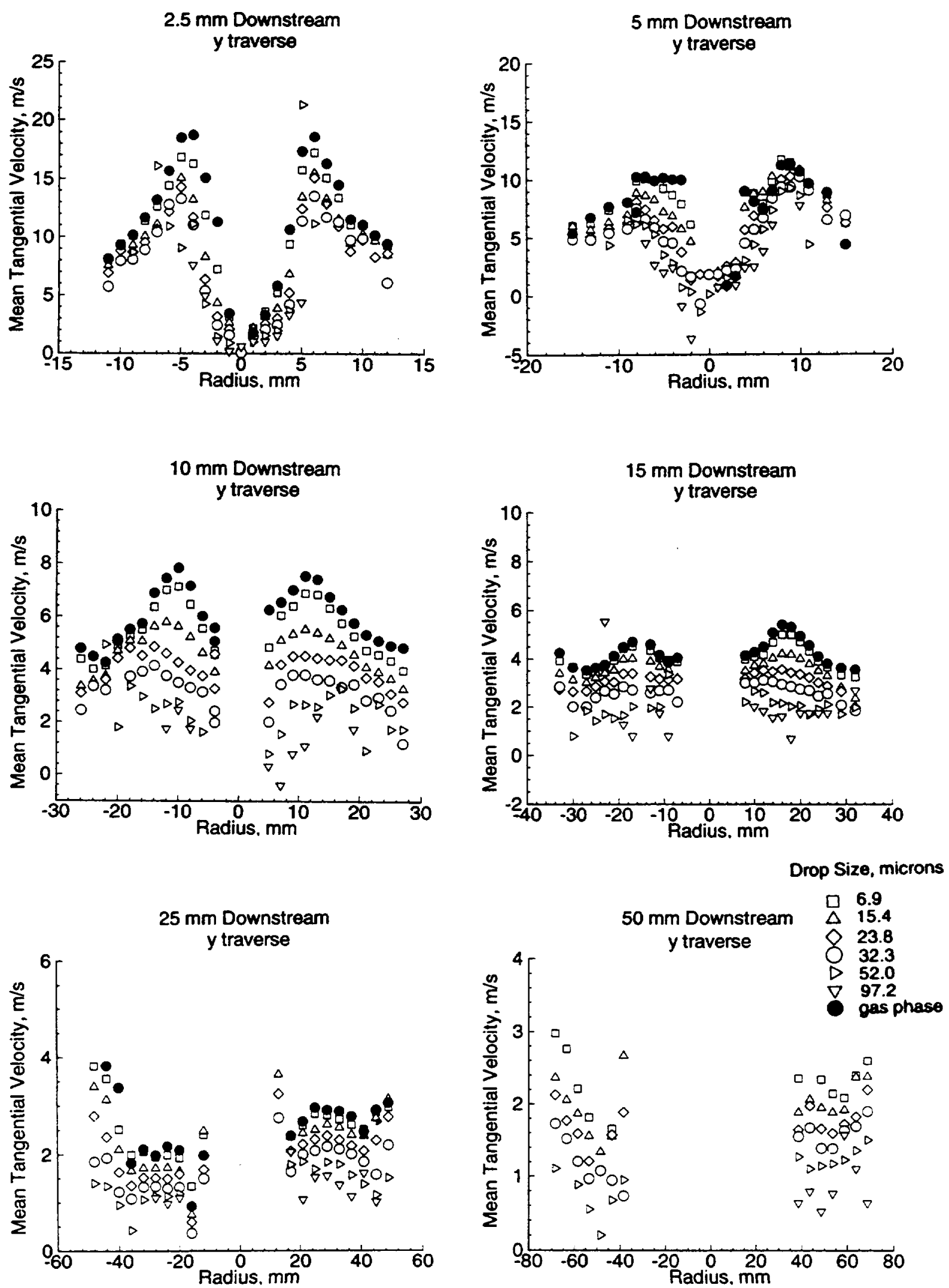

Figure 4.- Mean tangential velocity profiles. 

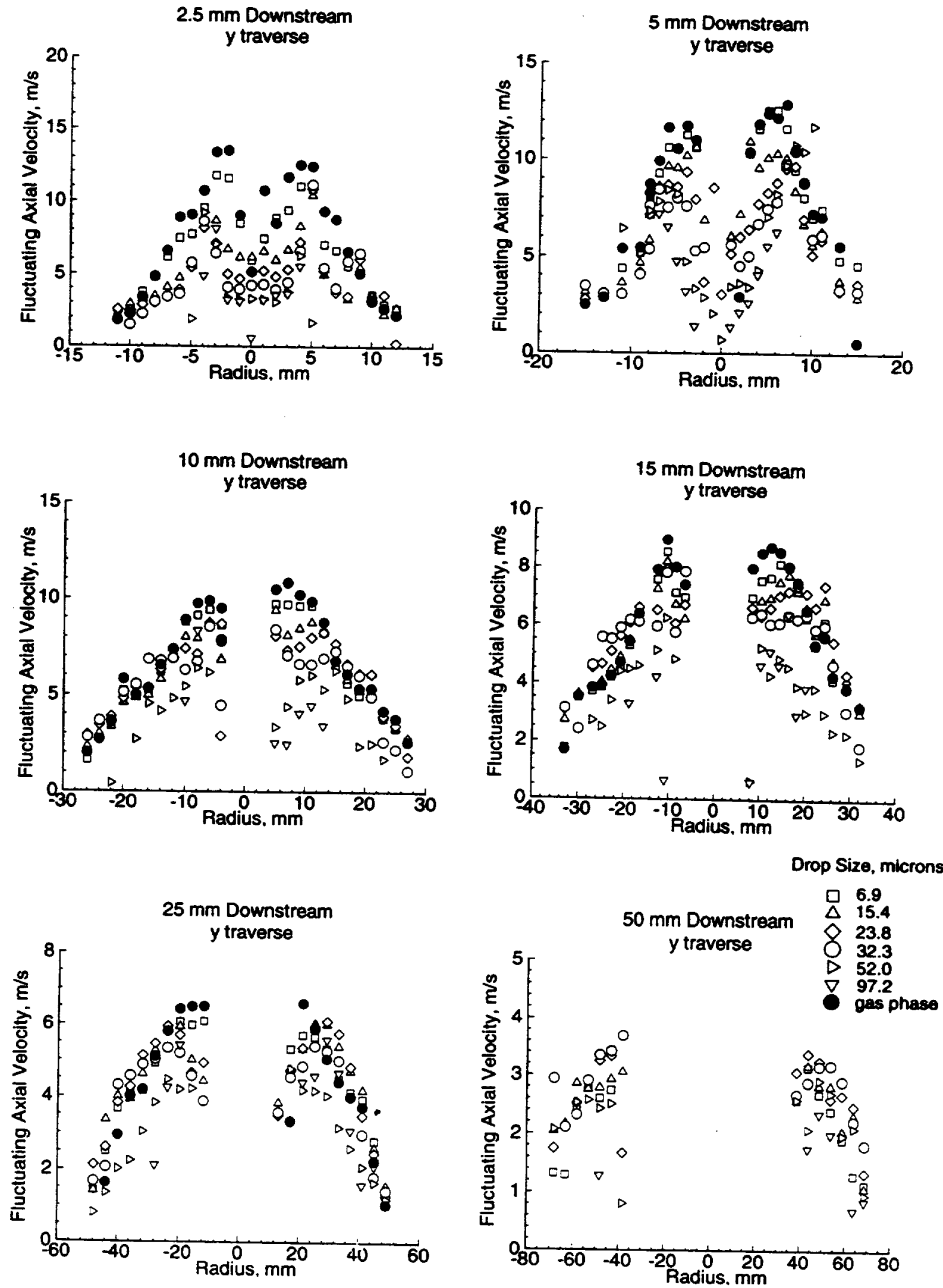

Figure 5.- Fluctuating axial velocity profiles. 

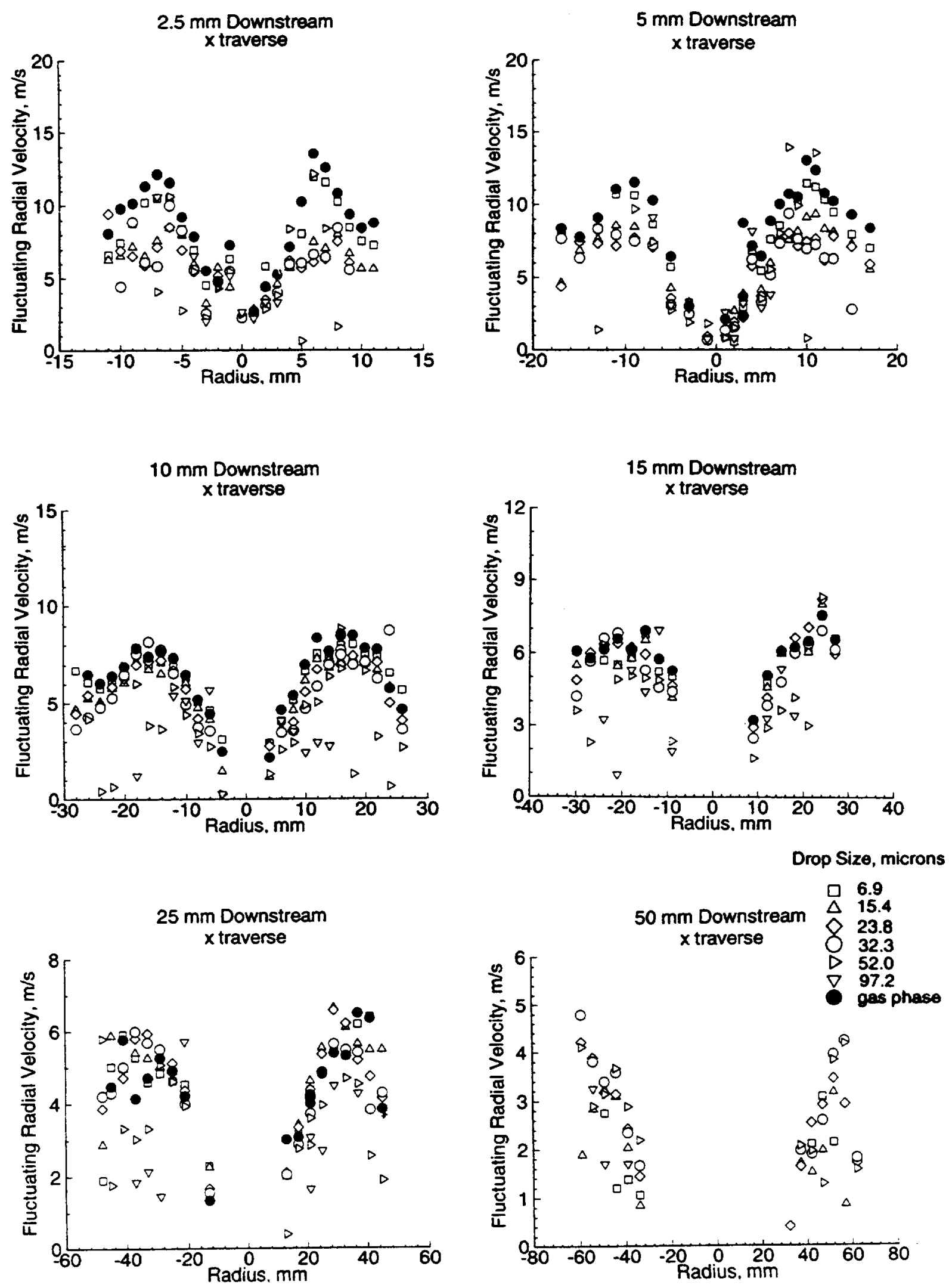

Figure 6.- Fluctuating radial velocity profiles. 

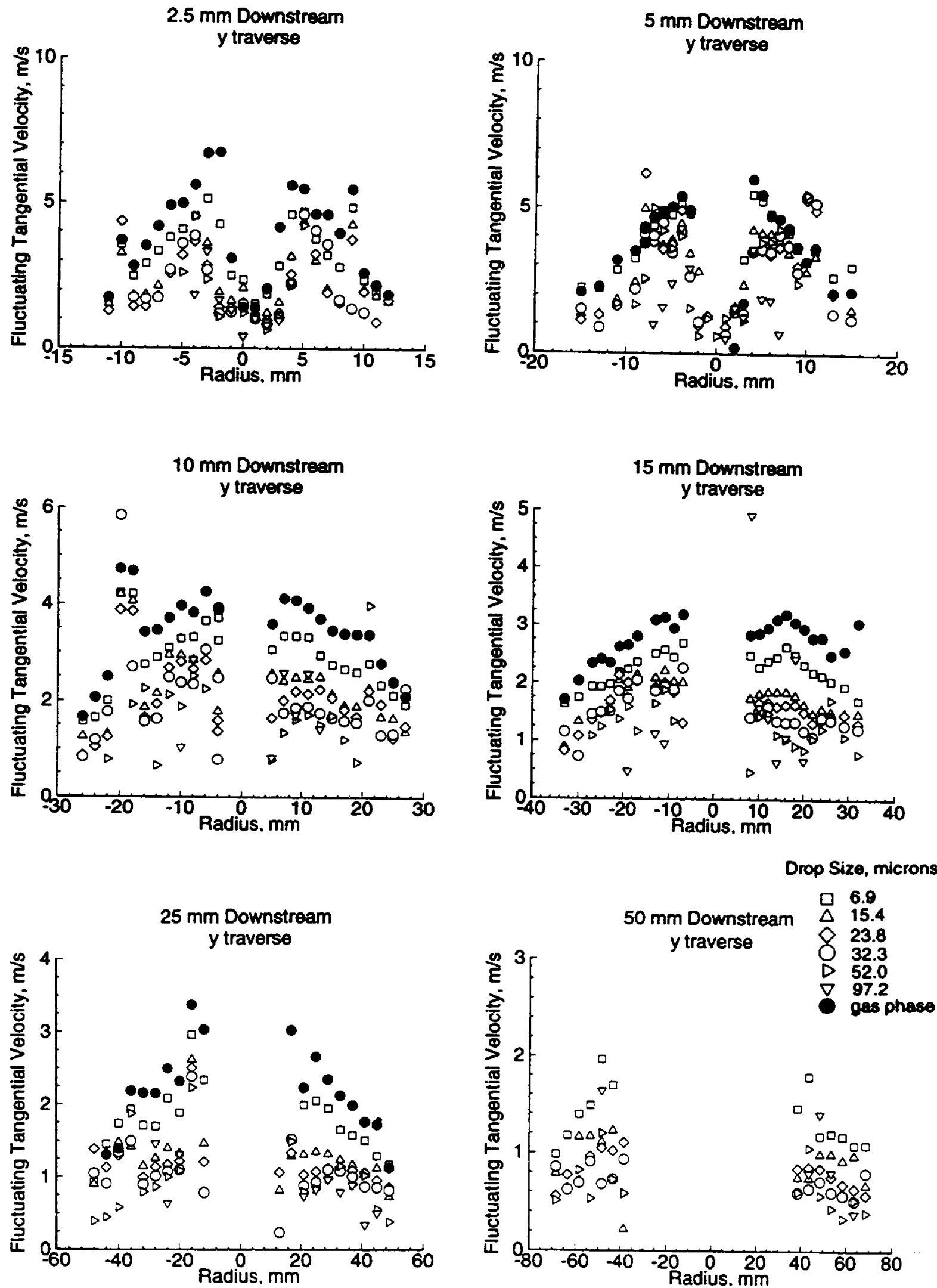

Figure 7.- Fluctuating tangential velocity profiles. 

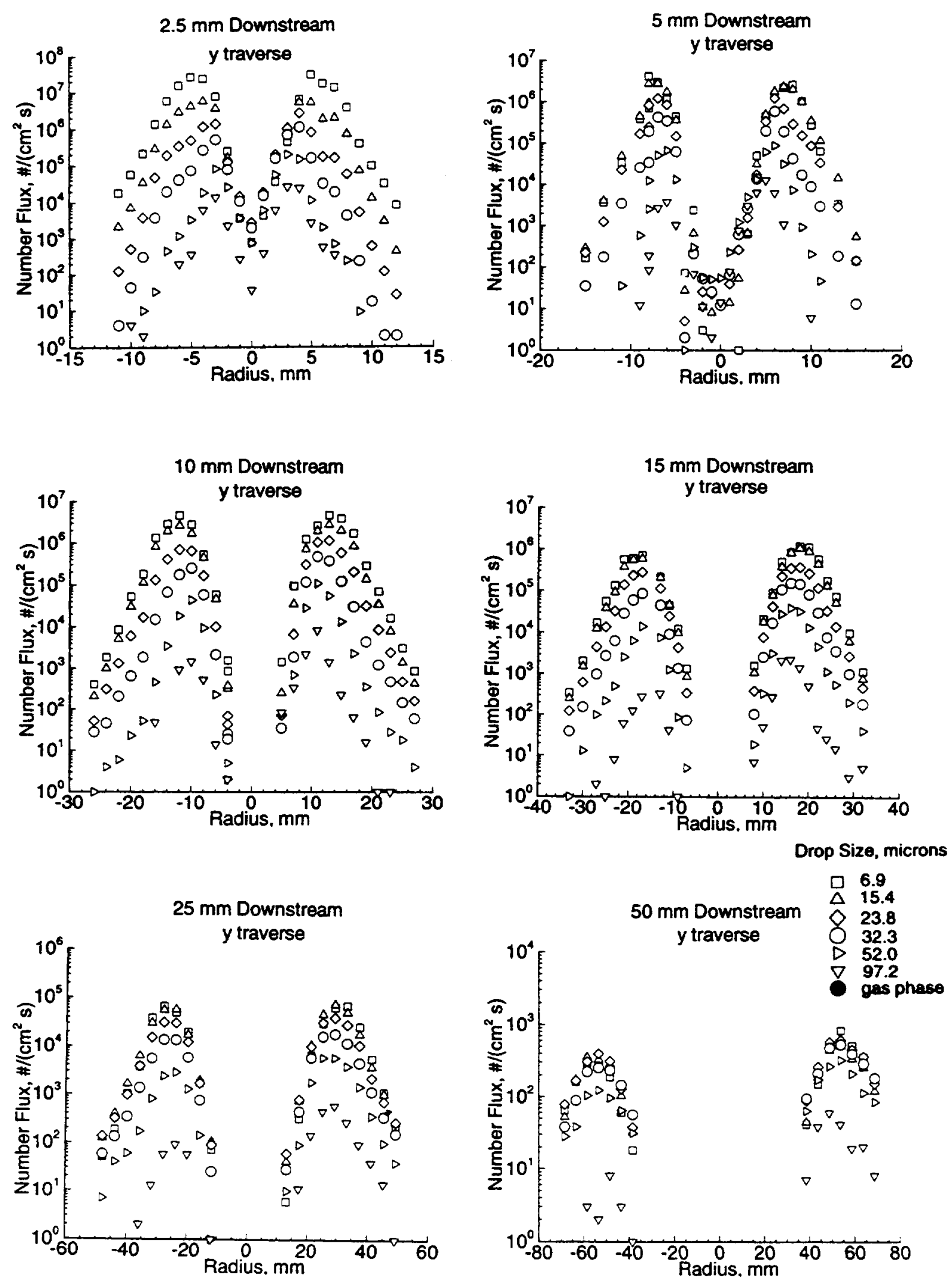

Figure 8.- Drop number-flux profiles. 


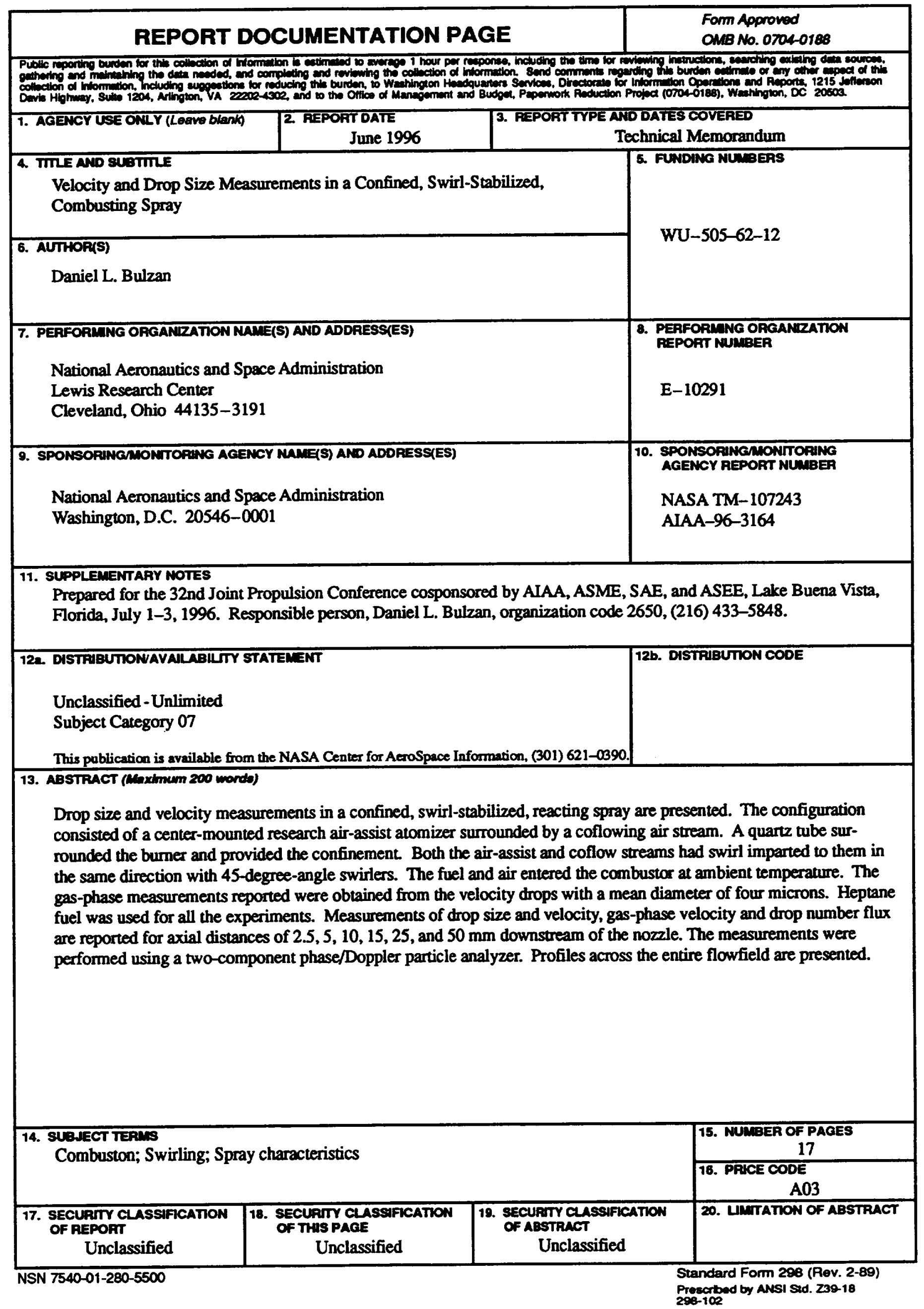





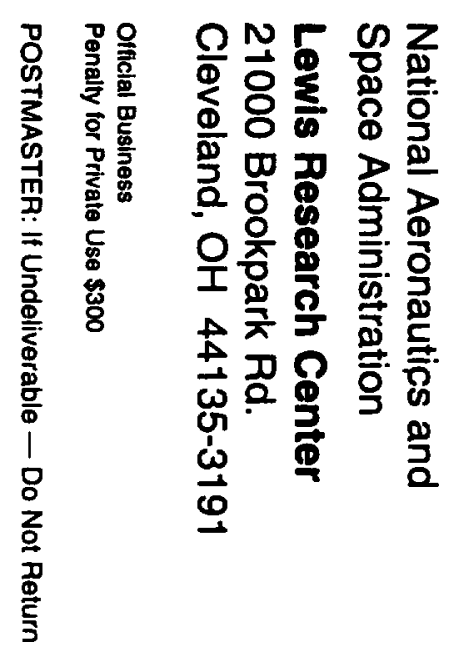

